Article

\title{
Proteomic profiling and rhizosphere-associated microbial com- munities reveal adaptive mechanisms of Dioclea apurensis Kunth in eastern Amazon's rehabilitating minelands
}

\author{
Sidney Vasconcelos do Nascimento ${ }^{1,2}$, Paulo Henrique de Oliveira Costa ${ }^{1}$, Héctor Herrera ${ }^{3}$, Cecílio Frois Caldeira \\ 1, Markus Gastauer 1, Silvio Junio Ramos 1, Guilherme Oliveira 1, Rafael Borges da Silva Valadares 1,* \\ 1 Instituto Tecnológico Vale, Rua Boaventura da Silva 955, Cep 66050-090, Belém, PA, Brazil. \\ sidney.nascimento@pq.itv.org (S.V.d.N.); paulo.henrique.costa@pq.itv.org (P.H.d.O.C.); \\ markus.gastauer@itv.org (M.G.); silvio.ramos@itv.org (S.J.R.); cecilio.caldeira@itv.org (C.F.C.); \\ guilherme.oliveira@itv.org (G.O.) \\ 2 Programa de Pós-Graduacão em Genética e Biologia Molecular. Universidade Federal do Pará, Belem, PA, \\ Brazil \\ 3 Departamento de Ciencias Forestales, Universidad de La Frontera, Temuco, Chile. \\ hector.herrera@ufrontera.cl (H.H.) \\ * Correspondence: rafael.borges.valadares@itv.org
}

\begin{abstract}
Dioclea apurensis Kunth is native to ferruginous rocky outcrops (known as canga) in the eastern Amazon. Native cangas are considered hotspots of biological diversity and have one of the largest iron ore deposits in the world. There, D. apurensis can grow in post-mining areas where molecular mechanisms and rhizospheric interactions with soil microorganisms are expected to contribute to their establishment in rehabilitating minelands. In this study, we compare the root proteomic profile and rhizosphere-associated bacterial and fungal communities of $D$. apurensis growing in canga and a rehabilitating mineland to characterize the main mechanisms that allow the growth and establishment in post-mining areas. The results showed that proteins involved in response to oxidative stress, drought, excess of iron, and phosphorus deficiency were more accumulated in canga and, therefore, helped explain its high establishment rates in rehabilitating minelands. Rhizospheric selectivity of microorganisms was more evident in canga. The microbial community structure was mostly different between the two habitats, denoting that despite having its preferences, $D$. apurensis can associate with beneficial soil microorganisms without specificity. Therefore, its good performance in rehabilitating minelands can also be improved or attributed to its ability to cope with beneficial soil-borne microorganisms. Native plants with such adaptations must be used to enhance the rehabilitation process.
\end{abstract}

Keywords: abiotic stress, proteomic, rehabilitating minelands, rhizosphere, symbiosis.

\section{Introduction}

Iron ore extraction in the eastern Amazon occurs mainly in ferruginous mountain outcrops surrounded by rainforests in the Carajás mineral province, covering some of the largest iron reservoirs of the world [1]. This ecosystem is characterized by a high plant diversity that forms different phytophysiognomies known as canga [2]. The plant communities that grow in canga are subjected to adverse environmental conditions such as intense ultraviolet (UV) radiation, high temperatures (soil and air), which, combined with constant winds, increase evapotranspiration processes [3]. At the same time, water acquisition is hampered by poor water-holding capacity influenced by soil composition and shallow soil formation, which tends to intensify the effects of water deficit $[2,3]$. Additionally, the oxidic soils from canga are characterized by low availability of soluble phosphorus $(\mathrm{P})$ caused by high adsorption of $\mathrm{P}$ to iron and aluminum oxides [4]. Plants require several adaptations to grow and colonize such ecosystems. A robust adaptive 
metabolism and symbiotic associations with soil microorganisms can lead to a successful establishment under these harsh environmental conditions.

Iron mining in Brazil occurs essentially in open-cast mines, including those in the Carajás mineral province [5]. The areas of iron ore extraction are characterized by the removal of vegetation and soil, and steep slopes [6]. Recent studies have evaluated different plants in the rehabilitation of areas affected by iron mining in the Amazon, including the reintroduction of native species [7]. These species have a crucial role in the success of mineland rehabilitation, reducing local biodiversity loss and contributing to the progressive recovery of ecological services associated with canga. Considering that revegetation is a fundamental technique for the rehabilitation of minelands, there is a need to identify native species able to cope with the stressful environmental conditions of postmining areas in canga and understand the adaptive mechanisms used by such plants [79].

Plants from the genus Dioclea (Fabaceae) can grow nearby mining areas in canga [10]. Considered a metallophyte species, Dioclea apurensis Kunth was listed as one of the most promising plants for mineland rehabilitation [11]. D. apurensis has been frequently used for the revegetation of waste piles and open-cast mines in rehabilitating minelands projects due to the ease of finding in native canga ecosystems, high seed production and rapid growth [12]. However, the molecular mechanisms underlining the establishment of this species in rehabilitating minelands have been scarcely explored.

Despite recognizing the importance of reintroducing native species for minelands rehabilitation, few studies analyze the protein profile of native plants used in rehabilitation programs and the interaction with microbiological communities in plants growing in post-mining areas. The aims of this study were: i) to analyze the protein profile of $D$. apurensis roots from plants growing in rehabilitating minelands; and ii) to identify rhizosphere microorganisms that contribute to the adaptation of $D$. apurensis in rehabilitating minelands. For this, we compare the protein profile and rhizosphereassociated microorganisms from plants growing in canga (their natural distribution habitat) and from plants growing in the rehabilitating minelands.

\section{Results}

\subsection{Physical and chemical properties of canga and mining area soil substrates}

The RM soil substrates showed a greater proportion of clay, while canga soils showed higher proportions of sand (Table 1). The soils from canga were more acidic than RM soils (Table 1). Canga soils showed more organic matter content than soils from RM (Table 1). Total nitrogen $(\mathrm{N})$ was higher in canga soils, whereas available phosphorus $(\mathrm{P})$ was higher in RM soil substrates (Table 1). The concentrations of metals differ between environments; copper and iron were higher in canga soils, whereas manganese and zinc were higher in RM soils (Table 1 ).

\subsection{Protein profiles, annotation, and functional enrichment}

A total of 1,401 proteins were successfully identified and quantified, with 396 showing significant differential accumulation $(\mathrm{p}<0.05)$ between roots from both environments (Dataset S1), being more accumulated in roots from canga. Only two proteins were exclusively detected in roots from RM, while 19 were identified only in roots from canga (Dataset S1). Within total proteins identified, 291 showed higher accumulation in roots from canga, while 105 were more accumulated in roots from RM. The PCA of the 1,401 proteins (Figure 1a) and 396 filtered proteins (Figure 1b) showed the separation between root samples from canga and roots from RM.

The enrichment analysis showed that the most accumulated proteins in canga act in 44 main processes, while the most accumulated proteins in RM participate in at least 20 processes (Figure 1c). In roots from both sampling sites, the most prominent categories included proteins involved in response to stimuli, mainly related to abiotic stresses, and 
proteins involved in growth and reproduction, including proteins involved in carbon metabolism and biosynthesis of secondary metabolites (Figure 1c). Proteins involved in these pathways, especially in secondary metabolite biosynthesis, including amino acid biosynthesis, and carbon metabolism, were more accumulated in canga. Figure S1a and $\mathrm{S} 1 \mathrm{~b}$ show the 40 main biological processes from the functional annotation of the most accumulated proteins in roots from canga and RM, respectively.

Table 1. Physical and chemical characteristics of soils associated with Dioclea apurensis growing in canga and rehabilitating minelands (RM). Soil results are mean \pm standard deviation for $\mathrm{n}=5$

\begin{tabular}{|c|c|c|}
\hline & $\mathbf{R M}$ & Canga \\
\hline Claya & $486.7 \pm 37.2$ & $287.5 \pm 103$ \\
\hline Silt ${ }^{\mathrm{a}}$ & $158.3 \pm 40.8$ & $87.5 \pm 75$ \\
\hline Sand ${ }^{a}$ & $355 \pm 68.9$ & $625 \pm 177$ \\
\hline $\mathrm{pH} \mathrm{H} \mathrm{H}_{2} \mathrm{O}$ & $6.1 \pm 0.3$ & $4.7 \pm 0.6$ \\
\hline $\mathrm{pH} \mathrm{CaCl} 2$ & $5.3 \pm 0.2$ & $4.2 \pm 0.3$ \\
\hline Available $\mathrm{P}^{\mathrm{b}}$ & $19.5 \pm 15.9$ & $1 \pm 0.9$ \\
\hline Total Nc & $0.1 \pm 0.06$ & $0.4 \pm 0.3$ \\
\hline Organic matter ${ }^{d}$ & $1.4 \pm 0.6$ & $7.7 \pm 0.9$ \\
\hline $\mathrm{Na}^{\mathrm{b}}$ & $4.7 \pm 0.6$ & $11.4 \pm 6.2$ \\
\hline $\mathrm{K}^{\mathrm{b}}$ & $22.6 \pm 6.8$ & $22.7 \pm 6.8$ \\
\hline $\mathrm{B}^{\mathrm{b}}$ & $0.1 \pm 0.03$ & $0.2 \pm 0.08$ \\
\hline $\mathrm{Cu}^{\mathrm{b}}$ & $0.6 \pm 0.3$ & $1.8 \pm 0.5$ \\
\hline $\mathrm{Fe}^{\mathrm{b}}$ & $11.3 \pm 6.3$ & $372 \pm 92$ \\
\hline $\mathrm{Mn}^{\mathrm{b}}$ & $59.7 \pm 9.4$ & $2.8 \pm 1.5$ \\
\hline $\mathrm{Zn}^{\mathrm{b}}$ & $2.1 \pm 1.6$ & $1.4 \pm 0.9$ \\
\hline \multicolumn{3}{|l|}{${ }^{a} \mathrm{~g} \mathrm{~kg}^{-1}$} \\
\hline \multicolumn{3}{|l|}{${ }^{\mathrm{b}} \mathrm{mg} \mathrm{dm^{-3 }}$} \\
\hline \multicolumn{3}{|l|}{ с \% } \\
\hline${ }^{\mathrm{d}}$ dag $\mathrm{kg}^{-1}$. & & \\
\hline
\end{tabular}

\subsection{Protein-protein interactions}

The analysis of protein-protein interactions (PPIs) showed 178 proteins with higher accumulation in roots from canga (Figure 2, Dataset S2) and 69 proteins in roots from RM (Figure 2, Dataset S2). The enrichment and PPI analysis showed an essential co-occurrence of a large part of the proteins accumulated in plants of each environment. These proteins were grouped into three highly interacting protein clusters, with a PPI enrichment $p$-value of $1 \times 10^{-16}$ in canga plants and $p$-value $<1.4 \times 10^{-6-}$ in RM plants (Figure 2, Dataset S2). 
a

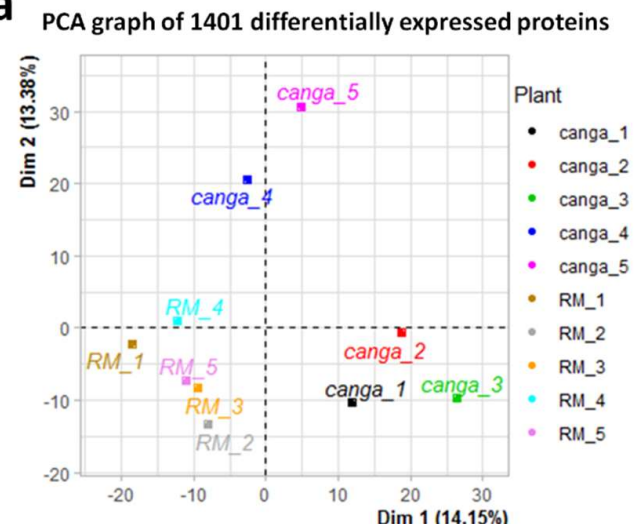

b

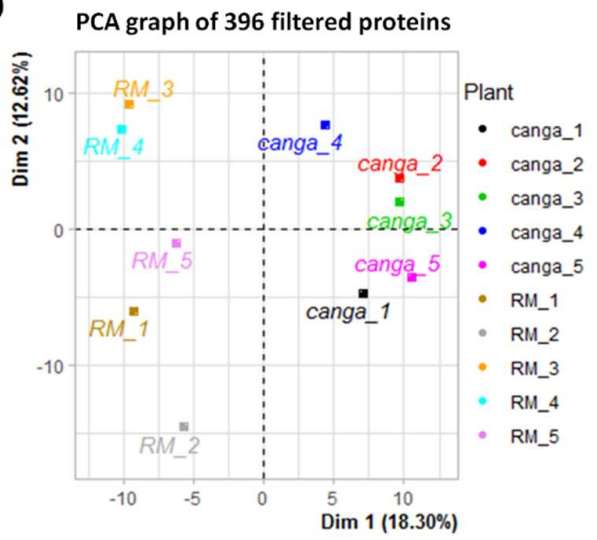

C

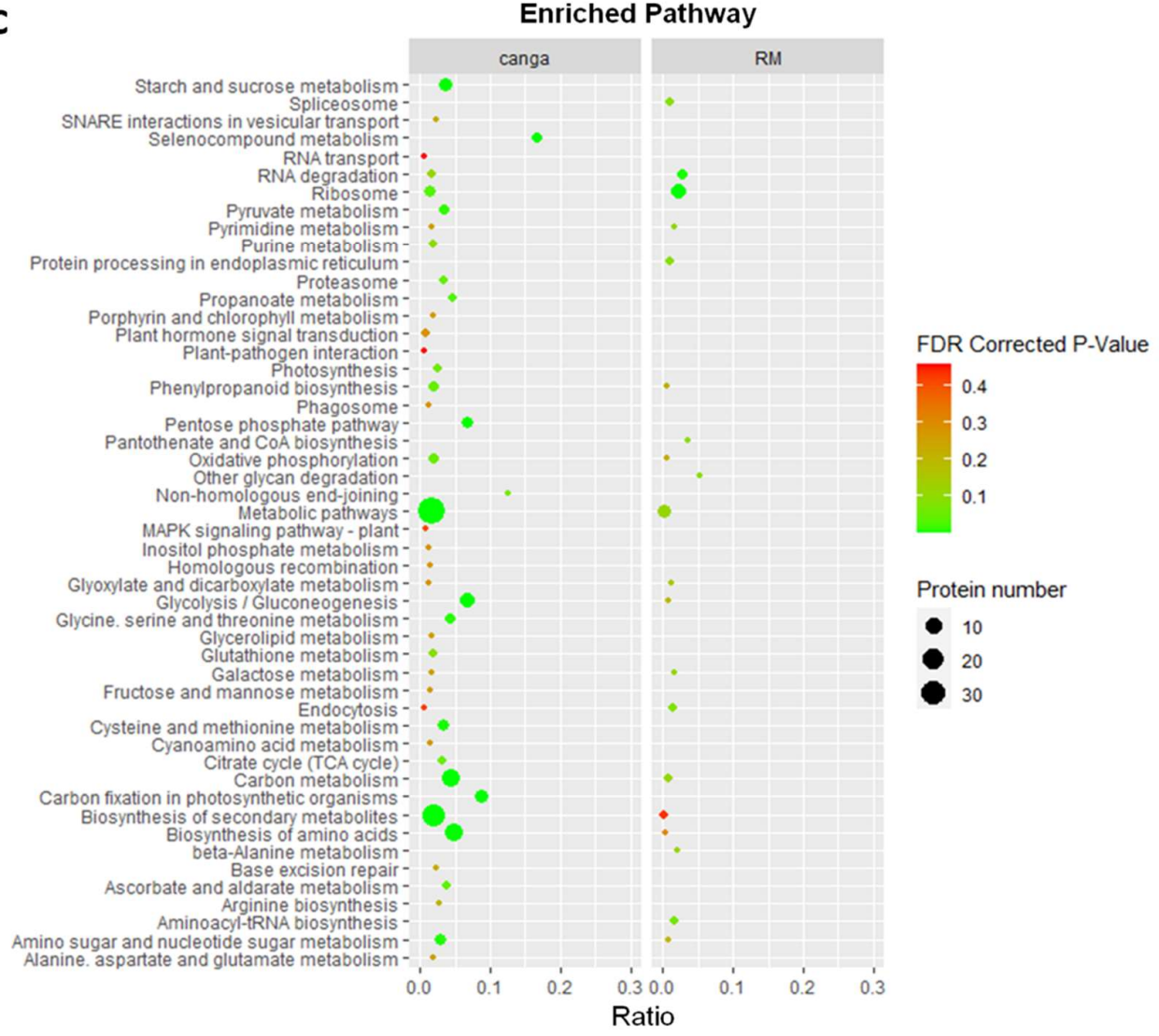

Figure 1. PCA and Enrichment analysis of the most differentially accumulated proteins in D. apurensis roots sampled from canga (canga) or in rehabilitating mineland (RM). (a) PCA of 1401 differentially accumulated proteins comparing five plants from canga with five from RM. (b) PCA of differentially accumulated and filtered proteins based on $p<0.05$ and fold change $\geq 1.5$. (c) Enrichment analysis of the most accumulated proteins in different biological processes. The significantly enriched KEGG pathways were indicated as dots (FDR corrected P $<0.05$, Fisher's exact test, Benjamini and Hochberg FDR correction method). The dot sizes represent the number of proteins included in each pathway. The x-axis represents the ratio of the number of differentially accumulated proteins and the number of all proteins in the pathway.

In canga plants, the functional enrichment analysis showed that the cluster in red includes 63 proteins mainly involved in energy metabolism and secondary metabolite biosynthesis, including amino acid biosynthesis. The green cluster composed 69 proteins related to the cell cycle and response, especially abiotic stresses such as osmotic stress. The blue cluster contains 46 proteins, mainly including binding proteins such as nucleic acid binding proteins, structural components of ribosomes, and protein folding. In RM plants, 
the red cluster was composed of 19 proteins related to abiotic stimuli, especially temperature. The cluster in green contains 24 proteins categorized by the functional enrichment analysis of the term "cellular anatomical entity," which includes proteins involved in carbon metabolism and biosynthesis of secondary metabolites. The 26 proteins included in the blue cluster of plants on RM were categorized mainly into cellular processes such as gene expression and protein metabolic process (Figure 2, Dataset S2).

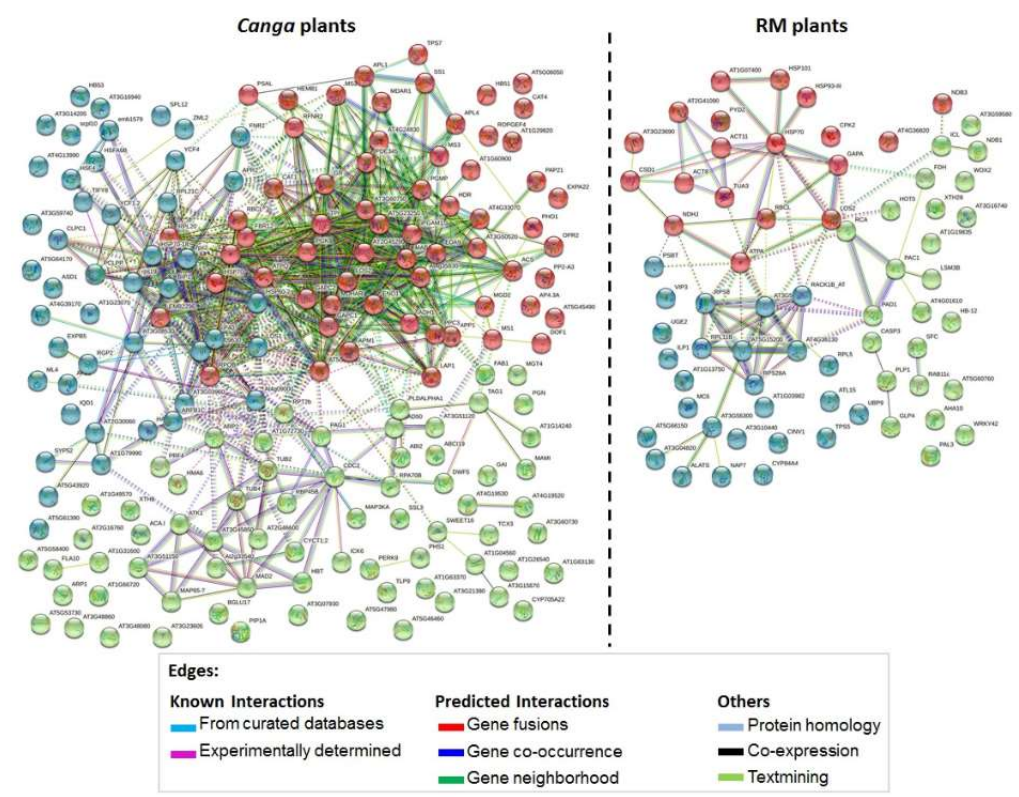

Figure 2. Protein-protein interaction network of the most differentially accumulated proteins in $D$. apurensis in canga (to the left) and RM (to the right) separated into $3 \mathrm{~K}$-means clusters illustrated in different colors. The proteins used for analysis are presented in Dataset S2. Gene symbols were obtained using homologous proteins from the Arabidopsis thaliana database from uniprot.org. Edges represent protein-protein interactions as described in the figure. Number of edges between in canga plants: 697. Number of edges between RM plants: 54 . Dotted lines represent edges between clusters. PPI enrichment $p$-value in canga plants: 1 x 10-16. PPI enrichment in RM plants: $<1.4 \times 10^{-6}$.

\subsection{Microbial diversity}

The ITS2 sequencing produced 3,948,832 raw reads across 16 input libraries. After quality filtering, 2,760,666 amplicon sequences were selected. The number of fungal OTUs in each sample ranged from 359 to 789 and was on average of 563 (Table S1). Canga soils showed more fungal sequences (1,404,745; comprising $521 \pm 132$ OTUs) than RM $(1,355,921$; comprising $605 \pm 97$ OTUs). Additionally, rhizosphere soil samples presented more sequences $(1,531,425$; comprising $634 \pm 116$ OTUs) than bulk soil samples $(1,229,241$; comprising $492 \pm 78$ OTUs). The Shannon and Simpson diversity indexes of fungal sequences were higher in RM, with higher values in the bulk soil substrates of RM samples (Figure 3).

The $16 \mathrm{~S}$ sequencing produced 4,208,259 raw reads across 16 input libraries. After quality filtering, 1,361,859 sequences were considered. The number of bacterial OTUs ranged from 205 to 996 and was on average 579 (Table S2). The soils from RM showed a higher number of sequences (769,122; comprising $723 \pm 240$ OTUs) than canga $(592,737$; comprising $435 \pm 190$ OTUs), whereas more bacterial sequences were detected in bulk soils (750,740; comprising $601 \pm 366)$ than in rhizosphere soils $(611,119$; comprising $556 \pm 76$ OTUs). The Shannon and Simpson diversity indexes were higher in the RM samples, with higher values in the rhizospheric substrate samples (Figure 3). 
a

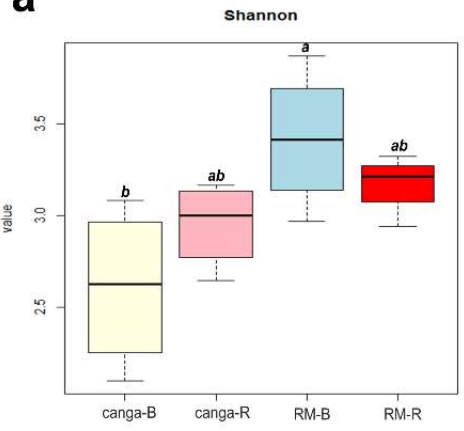

C

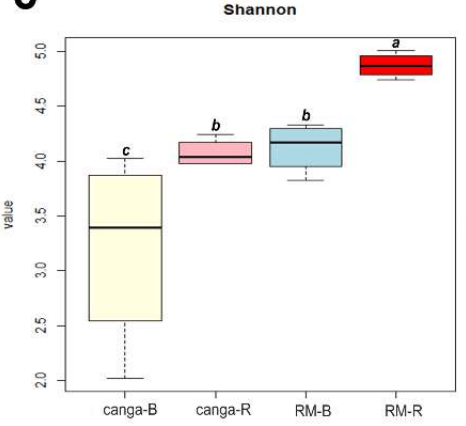

b

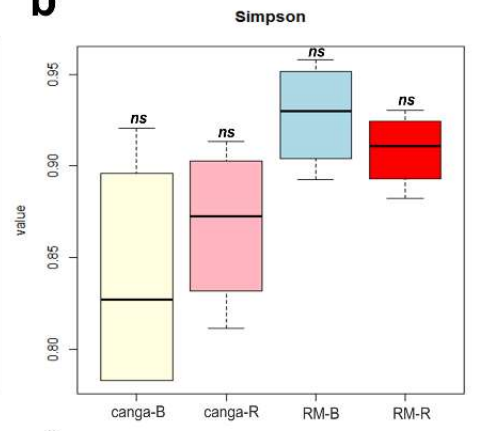

d

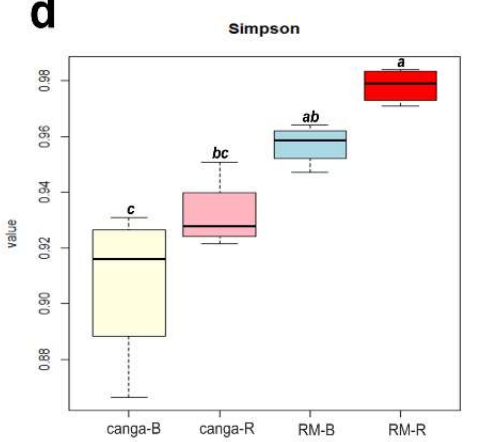

Figure 3. Alpha diversity (Shannon and Simpson) indices of sequences in rhizospheric and bulk substrates associated with $D$. apurensis growing in canga or rehabilitating minelands (RM). $(a, b)$ Indices of fungal 18S rRNA. (c, d) Indices of bacterial 16S rRNA. canga_B and RM_B, bulk substrate; canga_R and RM_R, rhizospheric substrate.

In canga, the analysis of fungal sequences showed Ascomycota and Basidiomycota as the most abundant phyla in the rhizosphere and bulk soils (Figure S2 and S3, Table S3). Glomeromycota was also detected in bulk soil samples (Figure S2 and S3, Table S3). Regarding bacterial sequences, Acidobacteria, Proteobacteria and Actinobacteria were the three most abundant phyla in the rhizosphere and bulk soils (Figure S2 and S3, Table S3).

In RM, the analysis of fungal sequences revealed Ascomycota, Basidiomycota, and Glomeromycota as the most dominant phyla in the rhizosphere and bulk soil substrate (Figure S2 and S3, Table S3). Proteobacteria, Acidobacteria, and Actinobacteria were the more abundant phyla in both rhizosphere and bulk soil substrates (Figure S2 and S3, Table S3).

A heatmap based on OTU abundance indicates differences between the structure of the microbial communities associated with plants in both ecosystems (RM and native canga) (Figure 4a and 4c). PCoA and cluster analyses of microbial community structure among the different samples showed that microbial communities were distinct between $\mathrm{RM}$ and native canga. Microbial communities also differed when comparing rhizospheric and bulk soil from canga (considering both fungal and bacterial populations) but not in RM (Figure $4 \mathrm{~b}$ and $4 \mathrm{~d}$ ).

Differences in the composition of microbial communities were estimated by calculating LEfSe scores at the family and genus levels. A total of 25 distinct fungal taxa were identified in plants established in canga or RM (Figure 5a). Most of these taxa were related to Ascomycota and Basidiomycota. Whereas a total of 29 preferential bacterial taxa were identified in plants growing in canga or RM, most of which were related to Proteobacteria and Actinobacteria (Figure 5b). 
a

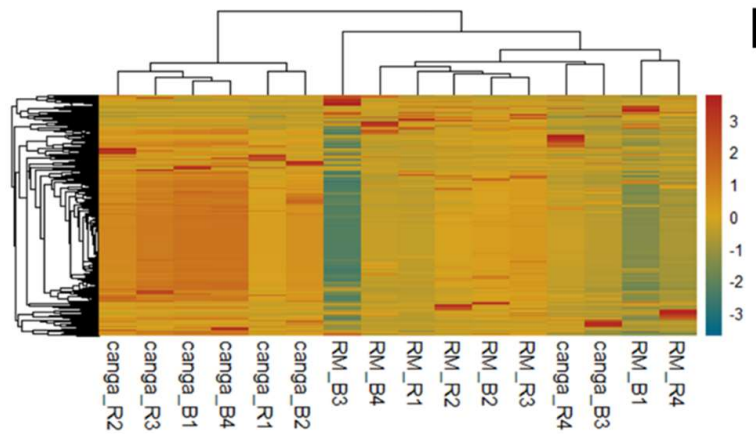

$\mathbf{C}$

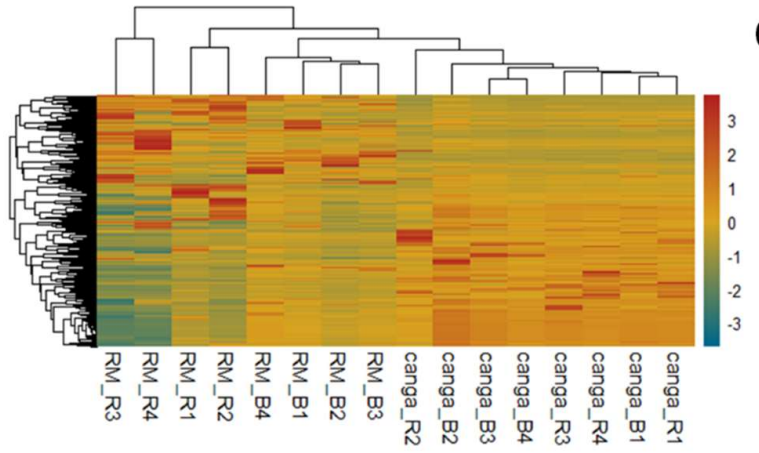

b

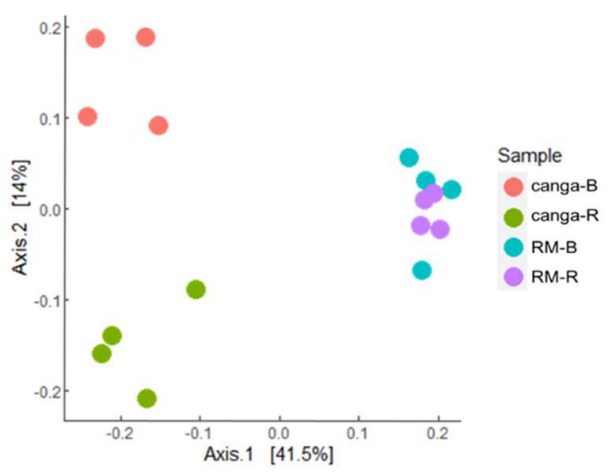

d

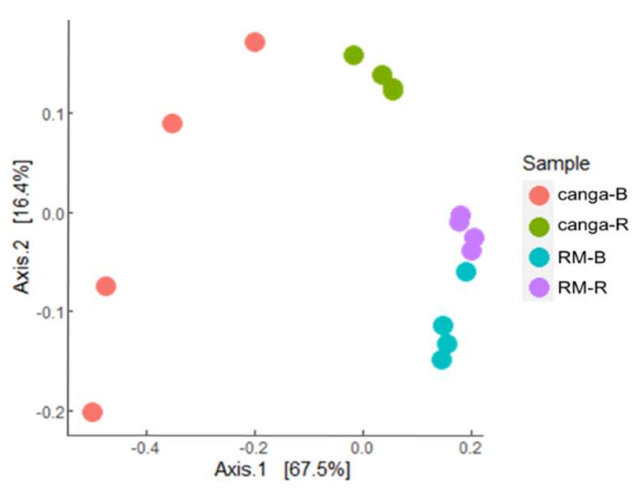

Figure 4. Heatmap and principal coordinate analysis for cumulative sum scaling (CSS)-normalized counts of the fungal 18S rRNA and bacterial 16S rRNA gene sequences obtained from substrates from D. apurensis growing in canga or rehabilitating minelands (RM). canga_B and RM_B, bulk substrate; canga_R and RM_R, rhizospheric substrate. $(a, b)$ Heatmap showing differences between fungal 18S rRNA (a) and principal coordinate analysis for cumulative sum scaling of fungal 18S rRNA (b). (c, d) Heatmap showing differences between bacterial 16S rRNA (c) and principal coordinate analysis for cumulative sum scaling of bacterial 16S rRNA (d).

a

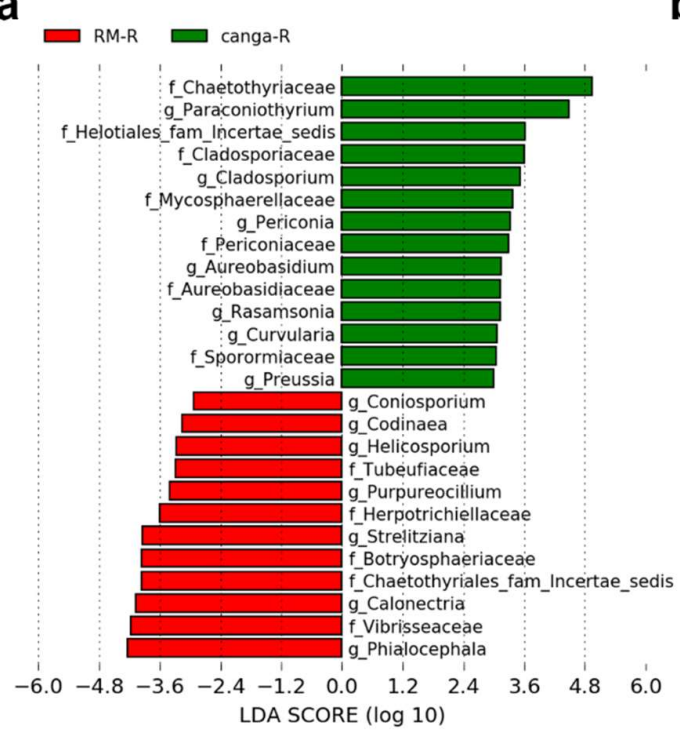

b

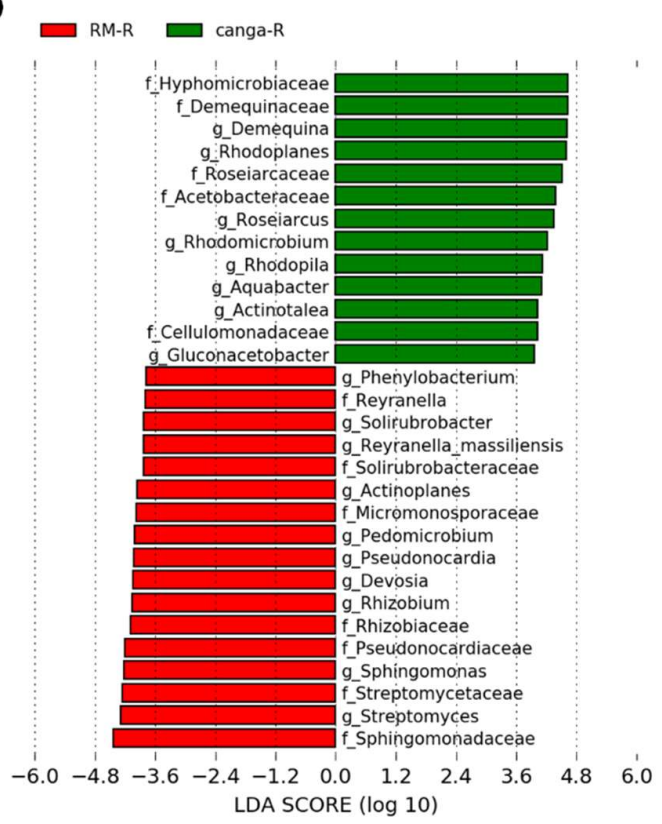

Figure 5. Linear discriminant analysis (LDA) of effect size (LEfSe) to identify preferential taxa in the rhizosphere of plants identified in canga (canga) or in rehabilitating minelands (RM). (a) preferential fungal 18S rRNA sequences and (b) preferential bacterial 16S rRNA sequences. 
A

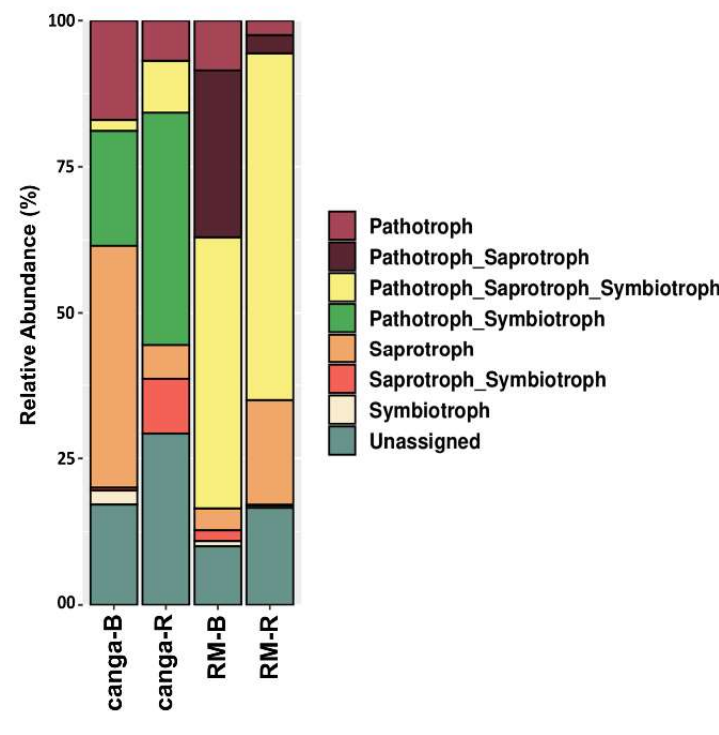

Seven trophic modes were predicted in the fungal OTUs, being the categories pathotroph_symbiotroph most abundant in soils from canga, whereas the categories pathotroph_saprotroph_symbiotroph were most abundant in soils from RM (Figure 6). Similarly, 36 predicted functions were identified in the bacterial OTUs, being the function nitrogen fixation and nitrate reduction more abundant in both soils but higher in the RM (Figure 6).

$\mathbf{B}$

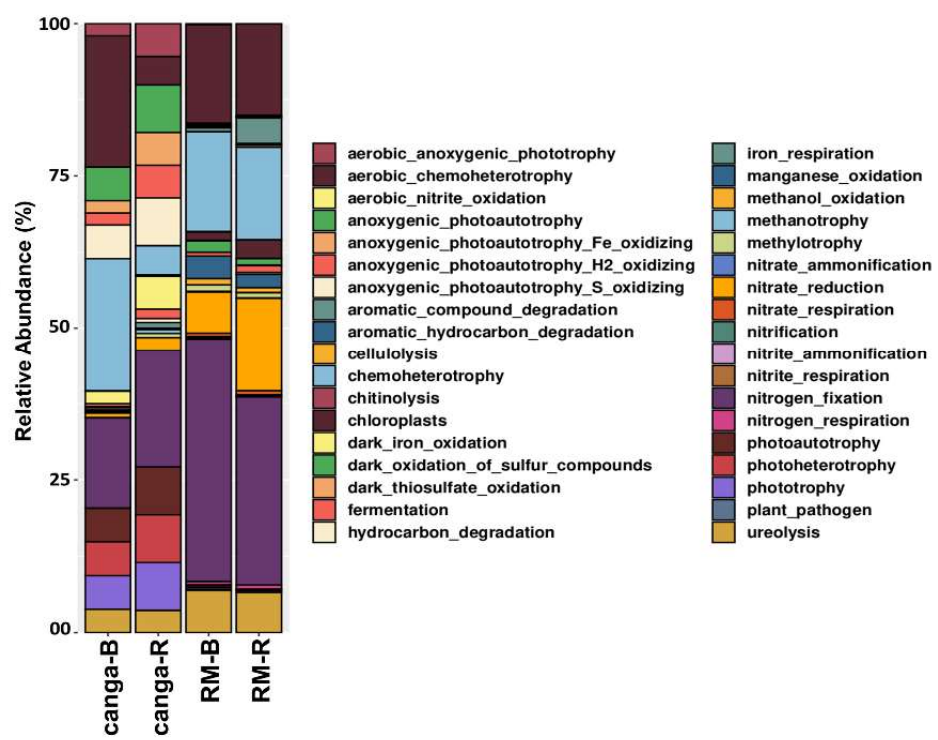

Figure 6. Functional analysis of the communities of $18 \mathrm{~S}$ rRNA (a) and bacterial $16 \mathrm{~S}$ rRNA (b) obtained from Dioclea apurensis rhizosphere from plants growing in a canga ecosystem (canga) or a rehabilitating mineland (RM) in Serra dos Carajás, eastern Amazon.

\section{Discussion}

In this study, the proteomic approach has revealed the expression of proteins related to metabolic pathways involved in response to the abiotic stress conditions of both native canga and RM. Together, the functional annotation, enrichment, and PPI analyzes showed the co-occurrence of a large part of the essential proteins accumulated in plants growing in each ecosystem and include those related to responses to oxidative stress, drought, $\mathrm{P}$ deprivation, excess iron, and symbiosis. Thus, the readiness of a molecular machinery joined to specific rhizosphere-associated fungal and bacterial communities inhabiting the rhizosphere can be considered crucial for establishing this native plant in rehabilitating minelands in the eastern Amazon.

\subsection{Physical and chemical properties of canga and mining area soil substrates}

Alteration in the normal levels of reactive oxygen species (ROS) is one of the main metabolic responses observed in plants growing under stressful environmental conditions [23]. In order to mediate the balance of ROS, the removal system relies on the action of enzymatic and non-enzymatic antioxidants [24]. In this study, proteins involved in synthesizing enzymatic antioxidants such as superoxide dismutase, peroxidases, catalases, glutathione reductase, and monodehydroascorbate reductase showed more accumulation in roots from canga (Dataset S1). Additionally, the non-enzymatic antioxidant systems proline-rich receptor protein kinase and betaine aldehyde dehydrogenase (BADH) were more accumulated in roots from canga (Dataset S1). Such results reveal the expression of proteins involved in the antioxidant system, especially in roots growing under the severe conditions of canga, which also are expressed in plants growing in rehabilitating minelands.

\subsection{Proteins involved in the response to water deficit}


Two types of aquaporins showed more accumulation in plants from canga, including aquaporin PIP1-1 and water-stress induced tonoplast intrinsic protein (Dataset S1), which play a regulatory role in the cellular transport of water in plasma membranes and tonoplasts, respectively [25]. These proteins have been described as essential for improving plant growth, water deficit tolerance, and osmotic balance [26,27]. Roots from canga showed a higher accumulation of proteins involved in abscisic acid (ABA) transport and signaling (i.e., phosphatase $2 \mathrm{C}$, ABC transporter, ATP-binding protein, ABC transporter $B$, and $A B C$ transporter $I)$, as well as proteins involved in signaling by serine/threonine kinase (i.e., phospholipase D alpha 1, proline-rich receptor-like protein kinase and receptor-like protein kinase S) than roots from RM (Dataset S1). ABA has been classified as a versatile phytohormone involved in plant signaling in response to drought stress [28]. Under conditions of water deficit (a common characteristic of canga ecosystems), there is also an accumulation of phosphatase 2C (PPC2) type proteins, which acts on the dephosphorylation of SnRK2, maintaining optimal ABA levels during water deficit [29], which agree with the results obtained in roots from plants growing in canga.

Accumulation of osmolytes such as glycine betaine (GB), which is synthesized in a pathway in which BADH acts as a critical enzyme, has been recently described in plants growing under abiotic stress, including the water deficit [30], contributing to a higher relative water content, the integrity of cell membranes, stabilization of proteins and detoxification [31]. The relationship of overexpression for BADH biosynthesis with the increase in GB levels and greater tolerance to water deficit has already been observed in plants such as Arabidopsis thaliana [31], Sesuvium portulacastrum [32], and Zea mays [33]. In addition to BADH, roots from canga showed a higher accumulation of proline-rich receptorlike protein kinase and spermidine synthase (Dataset S1). These proteins have been considered essential components of the cell membrane, playing essential roles in signal transduction in response to drought and stomata activity to prevent water loss [34,35]. The greater accumulation of these water deficit-responsive proteins in roots from canga indicates that $D$. apurensis have developed adaptive mechanisms to resist extensive drought periods in canga and help resist the drought events in rehabilitating minelands.

\subsection{Proteins involved in the response to metal stress}

Metal stress directly influences the establishment and growth of plants in mining areas. In fact, soils from canga showed higher levels of Fe (Table 1). High levels of metals in the soil solution can activate distinct signaling pathways such as cadmium-dependent, mitogen-activated protein kinase, ROS, and phytohormones, enhancing the expression of transcription factors or stress-responsive genes [36]. Most of these proteins were more accumulated in roots from canga (Dataset S1). Protein kinases, calmodulins, and calciumdependent protein kinases have been described as receptors capable of activating signaling networks in the tolerance to the excess of metals $[37,38]$.

Additionally, Glutathione-related proteins are directly involved in the balance of metals in the intracellular medium, a process that has been described in Cucumis sativus, Triticum aestivum, and Beta vulgaris [39,40]. These results also agree with Jiang et al. [41], who reported a direct role of heat shock proteins (HSP70) in the contribution of tolerance to metal stress in Rosa hybrida. Such proteins were more accumulated in roots from canga (Dataset S1). Similarly, proteins related to the biosynthesis of compounds commonly detected in plants growing under metal stress, such as phenylalanine ammonia-lyase and nicotianamine synthase, were detected in this study (Dataset S1) [42-44]. Additionally, ferritin was also more accumulated in roots from canga, and their role in cytoplasmatic sequestration of soluble iron $[42,43]$ can contribute to diminish the negative effects of the metal in D. apurensis.

\subsection{Proteins involved in the response to P-starvation}


According to this study, P levels in RM were higher than in canga (Table 1). The higher concentration of P in RM can be explained by hydroseeding containing NPK fertilization in these sites. Phosphorus deficiency in canga can be related to the formation of complexes between $\mathrm{P}$ and iron oxides, limiting plant uptake availability [45]. Roots from plants sampled in canga showed more proteins related to P depletion, such as monogalactosyldiacylglycerol synthase 2, phospholipase, alcohol dehydrogenase, extracellular purple acid phosphatases, and antioxidant system proteins such as catalases and monodehydroascorbate reductases [46-48]. During Pi deprivation, glycolipids are transferred to extraplastid membranes, where they replace degraded phospholipids to meet the need for Pi essential for various biological processes in the cell. This membrane remodeling occurs in a process dependent on the activation of monogalactosyldiacylglycerol synthase induced by a low Pi level. Studies have already observed this pattern in leaves and roots with different plant species under Pi depletion, including Sesamum indicum, Zea mays, and Arabidopsis thaliana $[46,49,50]$.

Additionally, three phospholipase D alpha-1 proteins were also more accumulated in roots from canga (Dataset S1). Phospholipase induction has been observed in studies with plants during P starvation [47]. These proteins are involved in P storage and induction of root growth to tolerate P scarcity conditions [47], such as in canga. In this sense, D. apurensis from canga synthesize proteins that support the growth under low $\mathrm{P}$ levels or induce mineralization from the soil substrate in canga. This study showed that alcohol dehydrogenase $(\mathrm{ADH})$ was more accumulated in roots from canga (Dataset S1). The increase in $\mathrm{ADH}$ accumulation is in line with the results observed in studies with different plant species growing under P shortage. The high accumulation of this protein is observed together with increases in glycolysis and fermentation intermediaries, possibly related to cell expansion in Pi-limitation [51,52]. In acidic and Fe-rich soil substrates, such as the canga ecosystems, $\mathrm{P}$ can form complexes with iron oxides in an inaccessible form for absorption by plant roots [48]. This study identified extracellular purple acid phosphatases in roots from canga (Dataset S1). These proteins belong to a group of hydrolases induced by $\mathrm{P}$ deficiency, acting in recycling $\mathrm{P}$ from esters and anhydrides [48]. Additionally, $\mathrm{P}$ scarcity in canga soil substrates can induce ROS formation, which was also observed in roots from canga (Dataset S1) participating in the signaling of cellular responses and protein biosynthesis involved in adaptations to P starvation [53]. Under both conditions, the roots expressed transcription factors commonly reported under $\mathrm{P}$ shortage, including MYB, WRKY, and HLH (Dataset S1), which regulate the expression of target genes and define metabolic responses to $\mathrm{P}$ starvation [54,55]. The set of proteins accumulated in plants growing in canga should contribute to the adaptation of $D$. apurensis in this ecosystem, although there are still no impediments to its development in environments with optimal P levels as in RM.

\subsection{Proteins involved in symbiosis}

Under abiotic stress, plants depend on beneficial soil microorganisms to become established in harmful environments such as canga. In this study, the analyses have detected several proteins involved in the establishment of symbiosis with bacteria and fungi, including nodulins [56], monodehydroascorbate ascorbate reductase [57], and enzymes involved in the ascorbate-glutathione cycle [58]. These enzymes were detected in roots from both ecosystems, with higher accumulation in roots from canga (Dataset S1). The nodulation in D. apurensis has been observed in recent studies with depletion of nutrients such as $\mathrm{N}$ [7]. Considering the successful establishment of D. apurensis in canga, these species contribute to maintaining essential soil processes such as $\mathrm{N}$ fixation during mineland rehabilitation [7,59]. The higher accumulation of symbiosis-related proteins in roots from canga than from RM is explained by the higher diversity of plant species found in canga ecosystems and their corresponding effect on soil microbial communities.

\subsection{Rhizosphere-associated microbial communities}


The rhizosphere-associated fungal and bacterial community analysis showed that specific taxa are enriched in the rhizosphere of D. apurensis. Proteobacteria and Ascomycota were the most abundant bacterial and fungal phyla, respectively, in both rhizosphere and bulk soil substrates (Figure 5). Recent studies have reported similar results in plants growing in ecosystems affected by mining activities, where the soil microbial communities and specific mechanisms of abiotic stress tolerance can be considered key to promoting the phytostabilization towards rehabilitation of ecosystems services $[9,60]$. Among the preferential microorganisms identified in this study, several beneficial saprophytic, freeliving, symbiotic, and endophytic taxa were directly identified in the rhizospheric soil, especially in plants from canga, where specific fungal and bacterial taxa belonging to plant growth-promoting microorganisms were detected (e.g. Paraconiothyrium, Rasamsonia, Scytalidium, Rhodoplanes, Bradyrhizobium, Rhizobium, Roseiarcus and Actinotalea) (Table S3; Figure 5). Such results agree with recent studies analyzing the diversity of microbial communities associated with plants growing under stressful environmental conditions, where specific rhizosphere-associated microorganisms have been described as essential to promote plant establishment $[61,62]$. This study has also detected a higher microbial diversity in plants from RM (especially fungal taxa), which can be related to the presence of widespread soil microorganisms inhabiting the RM soil substrates, with competition-mediated co-existence, latent soil microbes, and low influence of plant species on the soil microbiota (compared to native canga). However, the predicted functions of microorganisms involved in N-fixation were more abundant in RM than canga (Figure 6), showing that low specificity for microbial taxa can also be a characteristic supporting the establishment of this species in rehabilitating minelands.

The rhizosphere-associated fungal and bacterial communities play an essential role in establishing native species in rehabilitating minelands $[63,64]$. Additionally, several beneficial bacterial and fungal genera with key roles in nutrient solubilization, plant growth promotion, defense against phytopathogens were detected (e.g., Glomeromycetes, Sphingomonas, Actinotalea, Rhizobium, Rasamsonia, Paraconiothyrium) [65-67]. Despite the higher diversity of rhizosphere-associated microorganisms identified in plants growing in RM, they were mostly different from those detected in canga, denoting that D. apurensis can associate with beneficial soil microorganisms inhabiting soil substrates in RM without an apparent specificity, similar to what has been described in Mimosa acutistipula [9]. Accordingly, the specific rhizosphere-associated microbial communities of D. apurensis, which is related to better performance under abiotic stress conditions in canga [68], must be considered in minelands rehabilitation projects to preserve essential microbe-mediated processes that can contribute to later successional stages of rehabilitation in Amazonian canga.

\section{Materials and Methods}

\subsection{Soil substrate sampling and chemical analyses}

Samples were collected at the end of the wet season (May 2018) in a native metalliferous savanna in Serra dos Carajás, Pará, northern Brazil. The sampling sites included: i) a native herbaceous shrub canga ecosystem with minimal anthropogenic intervention $\left(6^{\circ} 00^{\prime} 41.0\right.$ "S 50 $\left.17^{\prime} 45.0^{\prime \prime} \mathrm{W}\right)$; and ii) a rehabilitating minelands (RM) in waste piles of iron mining $\left(6^{\circ} 02^{\prime} 32.0^{\prime \prime S} 50^{\circ} 07^{\prime} 04.0^{\prime \prime} \mathrm{W}\right)$, with a revegetation program started in 2014 . The application of $D$. apurensis seeds was carried out by hydroseeding containing NPK fertilization with $04-14-08$ ( $8 \mathrm{~kg}$ for each $8 \times 12 \mathrm{~m}$ of soil substrate).

The region's climate is tropical warm with a rainy season from November to March and a dry season from May to September, an average annual rainfall of $2033 \mathrm{~mm}$, and temperatures varying between $25.1^{\circ} \mathrm{C}$ and $26.3^{\circ} \mathrm{C}$ [8,13]. Bulk soil samples $(\mathrm{n}=5)$ were collected near $D$. apurensis roots naturally growing in canga and from $D$. apurensis growing in an RM project, at a depth of $10 \mathrm{~cm}, 5 \mathrm{~m}$ away from each plant considering zones without other plants. Rhizospheric soil $(n=5)$ was taken by gently shaking the soil substrate adhered to the root system from plants growing in canga and RM. The samples of bulk soil 
were submitted to chemical and physical analyses. After being air-dried, the samples were sieved using a $2 \mathrm{~mm}$ mesh. The $\mathrm{pH}$ was determined in a 1:2.5 soil substrate to water ratio, and the organic carbon content was determined using the potassium dichromate $\left(\mathrm{K}_{2} \mathrm{Cr}_{2} \mathrm{O}_{7}\right)$ method. The available $\mathrm{P}, \mathrm{K}, \mathrm{B}, \mathrm{Zn}, \mathrm{Fe}, \mathrm{Mn}$, and $\mathrm{Cu}$ were determined using the Mehlich-1 method $\left(0.05 \mathrm{~mol} \mathrm{~L}^{-1} \mathrm{HCl}+0.0125 \mathrm{~mol} \mathrm{~L}^{-1} \mathrm{H}_{2} \mathrm{SO}_{4}\right), \mathrm{S}_{-} \mathrm{SO}_{4}^{-2}$ by calcium phosphate monobasic at $0.01 \mathrm{M}$, and the total $\mathrm{N}$ content was determined using the Kjeldahl method [14]. The soil texture was determined as described by Kettler, et al. [15].

\subsection{Root sampling and protein isolation}

Roots from five $D$. apurensis individual plants were collected at each sampling site, kept in a cold phenol/SDS (sodium dodecyl sulfate) buffer, and transported to the laboratory for further processing. Protein isolation, determination of protein concentrations, and further processing were performed according to the protocol proposed by Nascimento et al. [16], with minor modifications (Table S4).

\subsection{Proteome analysis}

The identification and quantification of proteins were performed in a nanoACQUITY UPLC ${ }^{\circledR}$ ultra-performance liquid chromatography (Milford, MA, USA), configured for fractionation in two dimensions as reported in Herrera et al. [17]. The data were processed using the Progenesis QI software (Waters) for identification and quantification, using the Viridiplantae database from UniProt (UniProtKB/swiss-prot, uniprot.org). Protein identification was accepted if the probability of identifying peptides was greater than $90 \%$ and proteins with $95 \%$. The significance levels of the differential accumulations of proteins were determined by applying the ANOVA test $(\mathrm{p}<0.05)$. To compare the proteome of $D$. apurensis grown in canga or RM, a principal component analysis (PCA) of the proteins with differential accumulation and with $\mathrm{p}<0.05$ were produced in the $\mathrm{R}$ software v3.6.3 ( $\mathrm{R}$ Core Team 2018; https://www.R-project.org), using packages FactoMineR, Factoshiny, and Factoextra. The functional annotation of proteins was performed using the OmicsBox v1.2.4 (bioBam) and Uniprot (UniProtKB/swiss-prot, uniprot.org). Kyoto Encyclopedia of Gene and Genome (KEGG) pathway enrichment analysis for proteins was performed using the KOBAS software v3.0. [18] (kobas.cbi.pku.edu.cn) with Arabidopsis thaliana as the background species for the analysis. The $\mathrm{R}$ package ggplot2 was used for the enriched KEGG pathways visualization. The protein-protein interaction networks were predicted based on functional analysis using the software STRING (research tool for recovering genes/proteins in interaction) v11.0 (http://string-db.org/), using homologous proteins from the Arabidopsis thaliana as the background species.

\subsection{Microbial diversity}

Total DNA was extracted from $0.25 \mathrm{~g}$ of soil using the PowerSoil DNA Isolation Kit (QIAGEN, Hilden, Germany), according to the manufacturer's recommendations. The DNA concentration was determined with the Qubit fluorometer (Thermo Fisher Scientific, Waltham, MA, USA), and the quality was verified in a $1 \%$ electrophoresis agarose gel.

The amplicon libraries for bacteria and fungi were prepared according to Costa et al. [9], with minor modifications. The 16S rRNA gene was amplified by PCR using the bacterial primer set S-D-Bact-0341-b-S-17-N (5'-TCGTCGGCAGCGTCAGATGTGTATAAGAGACAGCCTACGGGNGGCWGCAG-3') and S-D-Bact-0785-a-A-21-N (5'GTCTCGTGGGCTCGGAGATGTGTATAAGAGACAGGACTACHVGGG-

TATCTAATCC-3'). After a hot start at $95^{\circ} \mathrm{C}$ for $3 \mathrm{~min}, 35 \mathrm{PCR}$ amplification cycles at 95 ${ }^{\circ} \mathrm{C}$ for $30 \mathrm{seg}, 55^{\circ} \mathrm{C}$ for $30 \mathrm{seg}$, and $72{ }^{\circ} \mathrm{C}$ for $30 \mathrm{seg}$ were performed, followed by a final extension step at $72{ }^{\circ} \mathrm{C}$ for $5 \mathrm{~min}$. The ITS region of the $18 \mathrm{~S}$ rRNA gene was amplified by PCR using the primer set fITS7i (5'- TCGTCGGCAGCGTCAGATGTGTATAAGAGACAGGTGARTCATCGAATCTTTG-3') and ITS4i (5'-GTCTCGTGGGCTCGGAGATGTGTATAAGAGACAGTCCTCCGCTTATTGATATGC-3'). After a hot start at $94{ }^{\circ} \mathrm{C}$ for $2 \mathrm{~min}$, 
35 PCR amplification cycles at $94^{\circ} \mathrm{C}$ for $30 \mathrm{seg}, 56^{\circ} \mathrm{C}$ for $1 \mathrm{~min}$, and $72{ }^{\circ} \mathrm{C}$ for 30 seg were performed, followed by a final extension step at $72{ }^{\circ} \mathrm{C}$ for $7 \mathrm{~min}$.

The size and quality of the PCR fragments were estimated on an Agilent 2100 Bioanalyzer (Agilent Technologies, Santa Clara, CA, USA) using a DNA 1000 chip. The libraries were purified with the AMPure XP purification kit (Beckman Coulter, Brea, CA, USA) and further processed with the Nextera XT kit (Illumina, San Diego, CA, USA). The gene libraries were sequenced in a Miseq-Illumina platform using a MiSeq V3 reagent kit (600 cycles; Illumina) in the human and medical genetics laboratory at Universidade Federal do Pará (Belém, PA, Brazil).

The ITS and 16S sequences were analyzed using the Pipeline for MetaBarcoding Analysis (PIMBA), which allows the analysis of metabarcodes based on the pipeline QIIME [19]. The low-quality sequences were filtered and trimmed using PRINSEQ v0.20.4, and forward and reverse sequences were merged using PEAR v0.9.19 [20]. Reads were dereplicated, singletons removed, and the sequences were truncated to 200 for fungi and 240 for bacteria. Chimeras were filtered, and the sequences were grouped into operative taxonomic units (OTUs) using VSEARCH v2.8.2. The taxonomic assignment was developed using the UNITE database for fungi and the Ribosomal Database Project for bacteria [21,22]. Graphs were constructed considering the alpha and beta diversity in R software using the ggplot2 and vegan packages. Beta diversity was calculated, and principal coordinate analysis (PCoA) graphs were constructed using the "weighted UniFrac distances" in R software using the phyloseq package. Heatmaps were constructed with the total abundance of OTUs using R software (packages pheatmap and phyloseq). Alpha diversity was estimated using the vegan package with the Shannon and Simpson diversity indices. Additionally, clustering analyses of the data were performed using an "hclust" function with the options "methods = ward.D2" and "method.dist = correlation" from the pvclust package in the $\mathrm{R}$ software. Permutational multivariate analysis of variance was applied using the function "adonis" (vegan package). Linear discriminant analysis (LDA) effect size (LEfSe) was performed with the Kruskal-Wallis test, and the effect size was estimated with a logarithmic score of 2.0 in the LDA. Finally, the predicted ecological roles of the identified microbial taxa were assigned using FUNGuild v1.1 [26] and FAPROTAX v1.2.4 [27] in Python v3.8.2. The data were plotted in the $\mathrm{R}$ software using the viridis, dplyr, and scales packages.

\section{Conclusions}

This study showed that $D$. apurensis growing in native canga expresses a set of proteins involved in the response to environmental stress to cope with the abiotic stress challenges. Its ability to express a wide range of proteins in response to the challenging conditions of post-mining areas enhance $D$. apurensis establishment in rehabilitating minelands. Among them, the identification of proteins involved in the antioxidant system, response to water deficit, excess of metals, deficiency of P. Additionally, our results confirm that $D$. apurensis establish interactions with beneficial microbial taxa without specificity. The expression of specific proteins involved in response to severe environmental conditions and interaction with key microbes at the rhizosphere are characteristics that can be identified in native species to select and diversify the plant species used for mineland rehabilitation.

Supplementary Materials: Figure S1: Top 40 categories obtained by functional annotation in different biological processes. (a) Most accumulated proteins in canga plants and (b) the most accumulated proteins in rehabilitating minelands (RM) plants; Figure S2: Relative abundance at the phylum level of major fungal (A) and bacterial (B) sequences associated with the rhizosphere (R) or bulk soil (B) of Dioclea apurensis growing in canga (canga) or a rehabilitating mineland (RM) in Serra dos Carajás, eastern Amazon ( $n=4)$; Figure S3: Relative abundance at the genus level of major fungal (A) and bacterial (B) sequences associated with the rhizosphere (R) or bulk soil (B) of Dioclea apurensis growing in canga (canga) or a rehabilitating mineland (RM) in Serra dos Carajás, eastern Amazon (n =4); Table S1: Fungal $18 \mathrm{~S}$ rRNA sequences obtained in rhizospheric and bulk substrates samples from Dioclea apurensis growing in canga (canga) or rehabilitating minelands (RM); Table S2: Bacterial 
16S rRNA sequences obtained in rhizospheric and bulk substrates samples from Dioclea apurensis growing in canga (canga) or rehabilitating minelands (RM); Table S3: Most abundant fungal and bacterial taxa identified in Dioclea apurensis soil substrates in plants from canga (canga) and rehabilitating minelands (RM). Numbers between parentheses are the relative abundance percentage (RA $\%$ ) of each identified taxa; Table S4: Steps and procedures of protein extraction; Dataset S1: Protein report of 396 proteins with differential accumulation in canga and RM plants filtered based on $\mathrm{p}<$ 0.05 and fold change $\geq 1.5$; Dataset S2: PPI enrichment of Dioclea apurensis root proteins in STRING.

Author Contributions: Conceptualization, S.V.d.N. and R.B.d.S.V.; methodology, S.V.d.N, P.H.d.O.C. and R.B.d.S.V.; validation, P.H.d.O.C. P.H.d.O.C., R.B.d.S.V., and G.O.; formal analysis, S.V.d.N., P.H.d.O.C., C.F.C., H.H., M.G. and R.B.d.S.V.; resources, G.O. and R.B.d.S.V.; data curation, S.V.d.N.; writing - original draft preparation, S.V.d.N.; writing - review and editing, S.V.d.N., C.F.C., R.B.d.S.V., H.H., M.G., P.H.d.O.C., S.J.R. and G.O.; supervision, R.B.d.S.V. and G.O.; funding acquisition, G.O. All authors have read and agreed to the published version of the manuscript.

Funding: This research was funded by Vale S.A., project "Canga Biodiversity and Ecosystem Services". G.O. is a CNPq fellow and received funding from CAPES (88887.130628/2016-00), CNPq (444227/2018-0, 402756/2018-5, and 307479/2016-1), and the CABANA project (RCUK(BB/P027849/1).

Data Availability Statement: The sequences obtained in this study were deposited in the NCBI Sequence Read Archive (https://www.ncbi.nlm.nih.gov/sra/PRJNA690164) under the accession number PRJNA690164. The proteomic data was submitted to Massive repository under the accession MSV000087423 (https://massive.ucsd.edu/).

Acknowledgments: H.H. is thankful for the financial support of the Fondo Nacional de Desarrollo Científico y Tecnológico, grant number 3200134.

Conflicts of Interest: The authors declare no conflict of interest. The funders had no role in the design of the study; in the collection, analyses, or interpretation of data; in the writing of the manuscript, or in the decision to publish the results.

\section{References}

1. dos Santos, R.S.P.; Milanez, B. The Global Production Network for iron ore: materiality, corporate strategies, and social contestation in Brazil. The Extractive Industries and Society 2015, 2, 756-765.

2. Jacobi, C.M.; Do Carmo, F.F.; Vincent, R.C.; Stehmann, J.R. Plant communities on ironstone outcrops: a diverse and endangered Brazilian ecosystem. Biodiversity and Conservation 2007, 16, 2185-2200.

3. Skirycz, A.; Castilho, A.; Chaparro, C.; Carvalho, N.; Tzotzos, G.; Siqueira, J.O. Canga biodiversity, a matter of mining. Frontiers in Plant Science 2014, 5, 653.

4. Lehmann, J.; da Silva Cravo, M.; de Macêdo, J.L.V.; Moreira, A.; Schroth, G. Phosphorus management for perennial crops in central Amazonian upland soils. Plant and Soil 2001, 237, 309-319.

5. Gastauer, M.; Souza Filho, P.W.M.; Ramos, S.J.; Caldeira, C.F.; Silva, J.R.; Siqueira, J.O.; Neto, A.E.F. Mine land rehabilitation in Brazil: Goals and techniques in the context of legal requirements. Ambio 2019, 48, 74-88.

6. Carvalho, C.S.; Forester, B.R.; Mitre, S.K.; Alves, R.; Imperatriz-Fonseca, V.L.; Ramos, S.J.; Resende-Moreira, L.C.; Siqueira, J.O.; Trevelin, L.C.; Caldeira, C.F. Combining genotype, phenotype, and environmental data to delineate site-adjusted provenance strategies for ecological restoration. Molecular Ecology Resources 2021, 21, 44-58.

7. Ramos, S.J.; Gastauer, M.; Mitre, S.K.; Caldeira, C.F.; Silva, J.R.; Neto, A.E.F.; Oliveira, G.; Souza Filho, P.W.; Siqueira, J.O. Plant growth and nutrient use efficiency of two native Fabaceae species for mineland revegetation in the eastern Amazon. Journal of Forestry Research 2019, 1-7.

8. Gastauer, M.; de Medeiros Sarmento, P.S.; Santos, V.C.A.; Caldeira, C.F.; Ramos, S.J.; Teodoro, G.S.; Siqueira, J.O. Vegetative functional traits guide plant species selection for initial mineland rehabilitation. Ecological Engineering 2020, 148, 105763.

9. Costa, P.H.d.O.; Nascimento, S.V.d.; Herrera, H.; Gastauer, M.; Ramos, S.J.; Caldeira, C.F.; Oliveira, G.; Valadares, R.B.d.S. Non-Specific Interactions of Rhizospheric Microbial Communities Support the Establishment of Mimosa acutistipula var. ferrea in an Amazon Rehabilitating Mineland. Processes 2021, 9, 2079.

10. Queiroz, L.P.d. Leguminosas da caatinga; Universidad Estadual de Feira de Santana: 2009.

11. Ramos, S.J.; Caldeira, C.F.; Gastauer, M.; Costa, D.L.P.; Neto, A.E.F.; de Souza, F.B.M.; Souza-Filho, P.W.M.; Siqueira, J.O. Native leguminous plants for mineland revegetation in the eastern Amazon: seed characteristics and germination. New Forests 2019, 50, 859-872.

12. Giannini, T.C.; Giulietti, A.M.; Harley, R.M.; Viana, P.L.; Jaffe, R.; Alves, R.; Pinto, C.E.; Mota, N.F.; Caldeira Jr, C.F.; Imperatriz-Fonseca, V.L. Selecting plant species for practical restoration of degraded lands using a multiple-trait approach. Austral Ecology 2017, 42, 510-521. 
13. Viana, P.L.; Mota, N.F.d.O.; Gil, A.d.S.B.; Salino, A.; Zappi, D.C.; Harley, R.M.; Ilkiu-Borges, A.L.; Secco, R.d.S.; Almeida, T.E.; Watanabe, M.T.C. Flora das cangas da Serra dos Carajás, Pará, Brasil: história, área de estudos e metodologia. Rodriguésia 2016, 67, 1107-1124.

14. Kirk, P.L. Kjeldahl method for total nitrogen. Analytical chemistry 1950, 22, 354-358.

15. Kettler, T.; Doran, J.W.; Gilbert, T. Simplified method for soil particle-size determination to accompany soil-quality analyses. Soil Science Society of America Journal 2001, 65, 849-852.

16. do Nascimento, S.V.; Magalhaes, M.M.; Cunha, R.L.; de Oliveira Costa, P.H.; de Oliveira Alves, R.C.; de Oliveira, G.C.; da Silva Valadares, R.B. Differential accumulation of proteins in oil palms affected by fatal yellowing disease. PloS one 2018, 13.

17. Herrera, H.; Valadares, R.; Oliveira, G.; Fuentes, A.; Almonacid, L.; do Nascimento, S.V.; Bashan, Y.; Arriagada, C. Adaptation and tolerance mechanisms developed by mycorrhizal Bipinnula fimbriata plantlets (Orchidaceae) in a heavy metalpolluted ecosystem. Mycorrhiza 2018, 28, 651-663.

18. Mao, X.; Cai, T.; Olyarchuk, J.G.; Wei, L. Automated genome annotation and pathway identification using the KEGG Orthology (KO) as a controlled vocabulary. Bioinformatics 2005, 21, 3787-3793.

19. Oliveira, R.R.; Silva, R.L.; Nunes, G.L.; Oliveira, G. PIMBA: a PIpeline for MetaBarcoding Analysis. bioRxiv 2021.

20. Zhang, J.; Kobert, K.; Flouri, T.; Stamatakis, A. PEAR: a fast and accurate Illumina Paired-End reAd mergeR. Bioinformatics 2014, 30, 614-620.

21. Abarenkov, K.; Henrik Nilsson, R.; Larsson, K.H.; Alexander, I.J.; Eberhardt, U.; Erland, S.; Høiland, K.; Kjøller, R.; Larsson, E.; Pennanen, T. The UNITE database for molecular identification of fungi-recent updates and future perspectives. New Phytologist 2010, 186, 281-285.

22. Cole, J.R.; Wang, Q.; Fish, J.A.; Chai, B.; McGarrell, D.M.; Sun, Y.; Brown, C.T.; Porras-Alfaro, A.; Kuske, C.R.; Tiedje, J.M. Ribosomal Database Project: data and tools for high throughput rRNA analysis. Nucleic acids research 2014, 42, D633D642.

23. Xie, H.; Yang, D.-H.; Yao, H.; Bai, G.; Zhang, Y.-H.; Xiao, B.-G. iTRAQ-based quantitative proteomic analysis reveals proteomic changes in leaves of cultivated tobacco (Nicotiana tabacum) in response to drought stress. Biochemical and biophysical research communications 2016, 469, 768-775.

24. Ahmad, P.; Jaleel, C.A.; Salem, M.A.; Nabi, G.; Sharma, S. Roles of enzymatic and non-enzymatic antioxidants in plants during abiotic stress. Critical reviews in biotechnology 2010, 30, 161-175.

25. Li, R.; Wang, J.; Li, S.; Zhang, L.; Qi, C.; Weeda, S.; Zhao, B.; Ren, S.; Guo, Y.-D. Plasma membrane intrinsic proteins SIPIP2; 1, SIPIP2; 7 and SIPIP2; 5 conferring enhanced drought stress tolerance in tomato. Scientific reports 2016, 6, 1-15.

26. Caldeira, C.F.; Jeanguenin, L.; Chaumont, F.; Tardieu, F. Circadian rhythms of hydraulic conductance and growth are enhanced by drought and improve plant performance. Nature Communications 2014, 5, 1-9.

27. Paudel, I.; Gerbi, H.; Zisovich, A.; Sapir, G.; Ben-Dor, S.; Brumfeld, V.; Klein, T. Drought tolerance mechanisms and aquaporin expression of wild vs. cultivated pear tree species in the field. Environmental and Experimental Botany 2019, 167, 103832.

28. González-Villagra, J.; Kurepin, L.V.; Reyes-Díaz, M.M. Evaluating the involvement and interaction of abscisic acid and miRNA156 in the induction of anthocyanin biosynthesis in drought-stressed plants. Planta 2017, 246, $299-312$.

29. Baek, D.; Kim, M.C.; Kumar, D.; Park, B.; Cheong, M.S.; Choi, W.; Park, H.C.; Chun, H.J.; Park, H.J.; Lee, S.Y. AtPR5K2, a PR5-like receptor kinase, modulates plant responses to drought stress by phosphorylating protein phosphatase 2Cs. Frontiers in plant science 2019, 10, 1146.

30. Wang, F.; Wang, M.; Guo, C.; Wang, N.; Li, X.; Chen, H.; Dong, Y.; Chen, X.; Wang, Z.; Li, H. Cloning and characterization of a novel betaine aldehyde dehydrogenase gene from Suaeda corniculata. Genet Mol Res 2016, 15.

31. Golestan Hashemi, F.S.; Ismail, M.R.; Rafii, M.Y.; Aslani, F.; Miah, G.; Muharam, F.M. Critical multifunctional role of the betaine aldehyde dehydrogenase gene in plants. Biotechnology \& Biotechnological Equipment 2018, 32, 815-829.

32. Yang, C.; Zhou, Y.; Fan, J.; Fu, Y.; Shen, L.; Yao, Y.; Li, R.; Fu, S.; Duan, R.; Hu, X. SpBADH of the halophyte Sesuvium portulacastrum strongly confers drought tolerance through ROS scavenging in transgenic Arabidopsis. Plant Physiology and Biochemistry 2015, 96, 377-387.

33. Zhang, L.; Gao, M.; Hu, J.; Zhang, X.; Wang, K.; Ashraf, M. Modulation role of abscisic acid (ABA) on growth, water relations and glycinebetaine metabolism in two maize (Zea mays L.) cultivars under drought stress. International journal of molecular sciences 2012, 13, 3189-3202.

34. Satish, L.; Rency, A.S.; Ramesh, M. Spermidine sprays alleviate the water deficit-induced oxidative stress in finger millet (Eleusine coracana L. Gaertn.) plants. 3 Biotech 2018, 8, 1-11.

35. Bai, L.; Zhang, G.; Zhou, Y.; Zhang, Z.; Wang, W.; Du, Y.; Wu, Z.; Song, C.P. Plasma membrane-associated proline-rich extensin-like receptor kinase 4 , a novel regulator of $\mathrm{Ca} 2+$ signalling, is required for abscisic acid responses in Arabidopsis thaliana. The Plant Journal 2009, 60, 314-327.

36. Tiwari, S.; Lata, C. Heavy metal stress, signaling, and tolerance due to plant-associated microbes: an overview. Frontiers in plant science 2018, 9, 452.

37. Jalmi, S.K.; Bhagat, P.K.; Verma, D.; Noryang, S.; Tayyeba, S.; Singh, K.; Sharma, D.; Sinha, A.K. Traversing the links between heavy metal stress and plant signaling. Frontiers in plant science 2018, 9, 12.

38. Zhao, D.; Li, T.; Wang, J.; Zhao, Z. Diverse strategies conferring extreme cadmium (Cd) tolerance in the dark septate endophyte (DSE), Exophiala pisciphila: evidence from RNA-seq data. Microbiological research 2015, 170, 27-35. 
39. Erbasol, I.; Bozdag, G.O.; Koc, A.; Pedas, P.; Karakaya, H.C. Characterization of two genes encoding metal tolerance proteins from Beta vulgaris subspecies maritima that confers manganese tolerance in yeast. Biometals 2013, 26, 795-804.

40. Vatansever, R.; Filiz, E.; Eroglu, S. Genome-wide exploration of metal tolerance protein (MTP) genes in common wheat (Triticum aestivum): insights into metal homeostasis and biofortification. Biometals 2017, 30, 217-235.

41. Jiang, C.; Bi, Y.; Zhang, R.; Feng, S. Expression of RcHSP70, heat shock protein 70 gene from Chinese rose, enhances host resistance to abiotic stresses. Scientific reports 2020, 10, 1-10.

42. Kottmann, L.; Wilde, P.; Schittenhelm, S. How do timing, duration, and intensity of drought stress affect the agronomic performance of winter rye? European Journal of Agronomy 2016, 75, 25-32.

43. Shevyakova, N.; Eshinimaeva, B.T.; Kuznetsov, V.V. Expression of ferritin gene in Mesembryanthemum crystallinum plants under different supply with iron and different intensity of oxidative stress. Russian Journal of Plant Physiology 2011, 58, 768-775.

44. Stein, R.J.; Ricachenevsky, F.K.; Fett, J.P. Differential regulation of the two rice ferritin genes (OsFER1 and OsFER2). Plant Science 2009, 177, 563-569.

45. Fink, J.R.; Inda, A.V.; Tiecher, T.; Barrón, V. Iron oxides and organic matter on soil phosphorus availability. Ciencia e agrotecnologia 2016, 40, 369-379.

46. Wang, F.; Ding, D.; Li, J.; He, L.; Xu, X.; Zhao, Y.; Yan, B.; Li, Z.; Xu, J. Characterisation of genes involved in galactolipids and sulfolipids metabolism in maize and Arabidopsis and their differential responses to phosphate deficiency. Functional Plant Biology 2020, 47, 279-292.

47. Lin, D.L.; Yao, H.Y.; Jia, L.H.; Tan, J.F.; Xu, Z.H.; Zheng, W.M.; Xue, H.W. Phospholipase D-derived phosphatidic acid promotes root hair development under phosphorus deficiency by suppressing vacuolar degradation of PIN-FORMED2. The New Phytologist 2020, 226, 142.

48. Tran, H.T.; Hurley, B.A.; Plaxton, W.C. Feeding hungry plants: the role of purple acid phosphatases in phosphate nutrition. Plant Science 2010, 179, 14-27.

49. Shimojima, M.; Watanabe, T.; Madoka, Y.; Koizumi, R.; Yamamoto, M.P.; Masuda, K.; Yamada, K.; Masuda, S.; Ohta, H. Differential regulation of two types of monogalactosyldiacylglycerol synthase in membrane lipid remodeling under phosphate-limited conditions in sesame plants. Frontiers in plant science 2013, 4, 469.

50. Shimojima, M.; Madoka, Y.; Fujiwara, R.; Murakawa, M.; Yoshitake, Y.; Ikeda, K.; Koizumi, R.; Endo, K.; Ozaki, K.; Ohta, $\mathrm{H}$. An engineered lipid remodeling system using a galactolipid synthase promoter during phosphate starvation enhances oil accumulation in plants. Frontiers in plant science 2015, 6, 664.

51. Alexova, R.; Millar, A.H. Proteomics of phosphate use and deprivation in plants. Proteomics 2013, 13, 609-623.

52. Chevalier, F.; Rossignol, M. Proteomic analysis of Arabidopsis thaliana ecotypes with contrasted root architecture in response to phosphate deficiency. Journal of plant physiology 2011, 168, 1885-1890.

53. Muneer, S.; Jeong, B.R. Proteomic analysis provides new insights in phosphorus homeostasis subjected to pi (inorganic phosphate) starvation in tomato plants (Solanum lycopersicum L.). PloS one 2015, 10.

54. Zhou, J.; Jiao, F.; Wu, Z.; Li, Y.; Wang, X.; He, X.; Zhong, W.; Wu, P. OsPHR2 is involved in phosphate-starvation signaling and excessive phosphate accumulation in shoots of plants. Plant Physiology 2008, 146, 1673-1686.

55. Aleksza, D.; Horváth, G.V.; Sándor, G.; Szabados, L. Proline accumulation is regulated by transcription factors associated with phosphate starvation. Plant Physiology 2017, 175, 555-567.

56. Sakamoto, K.; Ogiwara, N.; Kaji, T.; Sugimoto, Y.; Ueno, M.; Sonoda, M.; Matsui, A.; Ishida, J.; Tanaka, M.; Totoki, Y. Transcriptome analysis of soybean (Glycine max) root genes differentially expressed in rhizobial, arbuscular mycorrhizal, and dual symbiosis. Journal of plant research 2019, 132, 541-568.

57. Vadassery, J.; Tripathi, S.; Prasad, R.; Varma, A.; Oelmüller, R. Monodehydroascorbate reductase 2 and dehydroascorbate reductase 5 are crucial for a mutualistic interaction between Piriformospora indica and Arabidopsis. Journal of plant physiology 2009, 166, 1263-1274.

58. Luo, S.; Yin, J.; Peng, Y.; Xie, J.; Wu, H.; He, D.; Li, X.; Cheng, G. Glutathione is Involved in Detoxification of Peroxide and Root Nodule Symbiosis of Mesorhizobium huakuii. Current microbiology 2020, 77, 1-10.

59. Nunes, J.A.; Schaefer, C.E.; Ferreira Júnior, W.G.; Neri, A.V.; Correa, G.R.; Enright, N.J. Soil-vegetation relationships on a banded ironstone'island', Carajás Plateau, Brazilian Eastern Amazonia. Anais da Academia Brasileira de Ciências 2015, 87, 2097-2110.

60. Thavamani, P.; Samkumar, R.A.; Satheesh, V.; Subashchandrabose, S.R.; Ramadass, K.; Naidu, R.; Venkateswarlu, K.; Megharaj, M. Microbes from mined sites: harnessing their potential for reclamation of derelict mine sites. Environmental pollution 2017, 230, 495-505.

61. Fuentes, A.; Herrera, H.; Charles, T.C.; Arriagada, C. Fungal and Bacterial Microbiome Associated with the Rhizosphere of Native Plants from the Atacama Desert. Microorganisms 2020, 8, 209.

62. Herrera, H.; Novotná, A.; Ortiz, J.; Soto, J.; Arriagada, C. Isolation and identification of plant growth-promoting bacteria from rhizomes of Arachnitis uniflora, a fully mycoheterotrophic plant in southern Chile. Applied Soil Ecology 2020, 149, 103512.

63. Fowler, W.M.; Fontaine, J.B.; Enright, N.J.; Veber, W.P. Evaluating restoration potential of transferred topsoil. Applied Vegetation Science 2015, 18, 379-390.

64. Silva, J.R.; Gastauer, M.; Ramos, S.J.; Mitre, S.K.; Neto, A.E.F.; Siqueira, J.O.; Caldeira, C.F. Initial growth of Fabaceae species: Combined effects of topsoil and fertilizer application for mineland revegetation. Flora 2018, 246, 109-117. 
65. Dastogeer, K.M.; Li, H.; Sivasithamparam, K.; Wylie, S.J. In vitro salt and thermal tolerance of fungal endophytes of Nicotiana spp. growing in arid regions of north-western Australia. Archives of Phytopathology and Plant Protection 2018, 51, 602-616.

66. Oliveira, A.; Azarias Guimarães, A.; da Costa, A.M.; Louzada Rodrigues, T.; de Soares Carvalho, T.; Reis Sales, F.; de Souza Moreira, F.M. Plant growth-promoting rhizobacterial communities from an area under the influence of iron mining and from the adjacent phytophysiognomies which have high genetic diversity. Land Degradation \& Development 2020, 31, 2237-2254.

67. Zhan, F.; Li, B.; Jiang, M.; Li, T.; He, Y.; Li, Y.; Wang, Y. Effects of arbuscular mycorrhizal fungi on the growth and heavy metal accumulation of bermudagrass [Cynodon dactylon (L.) Pers.] grown in a lead-zinc mine wasteland. International journal of phytoremediation 2019, 21, 849-856.

68. Trindade, F.C.; Ramos, S.J.; Gastauer, M.; Saraiva, A.M.M.; Caldeira, C.F.; Oliveira, G.; da Silva Valadares, R.B. Metaproteomes reveal increased capacity for stress tolerance of soil microbes in ferruginous tropical rocky outcrops. Pedobiologia 2020, 81, 150664. 